Article

\title{
Diel and Seasonal Variations of Vocal Behavior of the Neotropical White-Tipped Dove (Leptotila verreauxi)
}

\author{
Cristian Pérez-Granados $1,2, *$ (D) and Karl-L. Schuchmann $1,3,4$ (D) \\ 1 National Institute for Science and Technology in Wetlands (INAU), Federal University of Mato \\ Grosso (UFMT), Computational Bioacoustics Research Unit (CO.BRA), Fernando Correa da Costa Av. 2367, \\ Cuiabá MT 78060-900, Brazil; klschuchmann@googlemail.com \\ 2 Postgraduate Program in Ecology and Biodiversity Conservation, Institute of Biosciences, Federal University \\ of Mato Grosso, Cuiabá MT 78060-900, Brazil \\ 3 Zoological Research Museum A. Koenig (ZFMK), Ornithology, Adenauerallee 160, 53113 Bonn, Germany \\ 4 Postgraduate Program in Zoology, Institute of Biosciences, Federal University of Mato Grosso, \\ Cuiabá MT 78060-900, Brazil \\ * Correspondence: perezgranadoscr@gmail.com
}

Received: 19 August 2020; Accepted: 14 October 2020; Published: 16 October 2020

check for updates

\begin{abstract}
Current knowledge regarding the vocal behavior in tropical non-passerines is very limited. Here, we employed passive acoustic monitoring to study the vocal activity of the white-tipped dove (Leptotila verreauxi) at three sites over a year in the Brazilian Pantanal. The diel pattern of vocal activity showed a bimodal pattern, with significantly higher vocal activity after sunrise than during the other hours of the day, in agreement with prior studies on this species and other members of Columbidae. The species was vocally active throughout the year, but vocal activity was maximum during May-June and lowest during January-February. Relative air humidity was positively associated with vocal activity, which may be related to the improvement of sound transmission under more humid conditions, but it could also be related to foraging efficiency due to a higher availability of invertebrates on wetter days. Vocal activity was not related to the mean air temperature or daily rainfall. Acoustic monitoring proved to be a useful tool for monitoring this shy forest species, for which a minimum number of three monitoring days was needed to detect a reliable vocal activity rate. Future studies should evaluate its use for monitoring other species of doves and pigeons that are secretive or threatened.
\end{abstract}

Keywords: acoustic monitoring; annual cycle; call; Columbidae; Kaleidoscope Pro; Pantanal; seasonality

\section{Introduction}

The study of avian acoustics has attracted the interest of ornithologists for centuries [1,2]. Birds vocalize to defend territories and attract mates, but they are also used to signal food resources and predators or to maintain group contact [3-5]. The vocal activity of birds is influenced by a large number of endogenous (e.g., breeding status and hormones; [6]) and exogenous factors (e.g., photoperiod, weather, moonlight, and background noise; [7]). Therefore, the study of diel and seasonal patterns in the vocal activity of birds may provide valuable information on the ecology of the monitored species and the context of vocal behavioral responses. However, despite the large number of studies addressing this topic [5,7], much work is still needed.

The lack of knowledge regarding avian vocal behavior is particularly apparent for tropical birds since they are less studied than birds from temperate zones $[7,8]$. However, the study of vocal behavior 
in tropical birds is interesting since most of the knowledge acquired in temperate areas on song function and its relationship to weather conditions and bird vocal activity may not be extrapolated to tropical regions [8,9]. Vocal behavior in tropical birds is less restricted to the breeding period than that occurring in temperate areas [10-12], involves large contributions of duets and female song [9], and can be affected by the presence of more diverse ecosystems [13]. Among tropical birds, most previous research on diel and seasonal variations in vocal behavior has involved passerines as target species (e.g., [10-12,14,15], but see [16]). Similarly, the majority of studies assessing the relationship between weather conditions and the vocal behavior of tropical birds have focused on passerines, with a limited number of studies testing the impact of weather conditions on non-passerines [8,17-19]. However, Passeriformes is just one of the 28 avian orders [20]. Therefore, it is interesting to perform detailed research on bird vocal behavior across a broader taxonomic spectrum, since vocal behavior and vocal ability may have evolved independently in different bird orders [7,21].

Passive acoustic monitoring is a promising method used to monitor vocally active wildlife species and its use has widely increased over the last decade [22]. This technique has proven to be especially helpful in replacing field surveys when direct counts or visual surveys are logistically difficult or involve high monetary and time efforts [22,23]. Acoustic monitoring is also an alternative method for monitoring common bird species under adequate environmental conditions (e.g., windless and rainless days, [24,25]), but also for monitoring birds inhabiting inhospitable or difficult-to-access sites, such as islands and rainforests [26,27], as well as for surveying nocturnal and rare species [18,28]. Passive acoustic monitoring has also allowed researchers to study the vocal behavior of several tropical bird species (e.g., [11,14,15]), but it has been rarely applied to study bird vocal behavior, particularly at a large temporal scale.

The white-tipped dove (Leptotila verreauxi) is a common resident bird species in the Brazilian Pantanal for which available information about its ecology and vocal behavior is very limited. It is a large and widespread Neotropical diurnal dove that can be found in scrub, woodland, and forest habitats, but also occurs in southernmost Texas and central Argentina [29]. The white-tipped dove is classified as a least-concern species by the International Union for Conservation of Nature [30]. This non-flocking species is usually found individually or in pairs [31,32] and is omnivorous, foraging mostly on the ground within vegetation to feed on seeds, berries, and insects. The species has been considered shy and wary [29], which may explain the reduced knowledge about its ecology (but see [31-34]). The best method for monitoring this species is by detecting its particular call, which was described by Skutch (1964) as "one of the most characteristic bird notes through large part of the year" in Central America. We selected the white-tipped dove as a study species because we aimed to improve our understanding about the vocal behavior of tropical non-passerines, and because its secretive behavior combined with its particular call suggests that the use of passive acoustic monitoring might be a potential solution for obtaining new life history information on this enigmatic species. The call of the white-tipped dove consists of two mournful notes at the same pitch (Figure 1). The call starts with an introductory hoot followed by a longer, more audible, hollow note, "woo-woooooo" ([32], Figure 1). The same individual may sing repeatedly every 5-10 s [29]. 


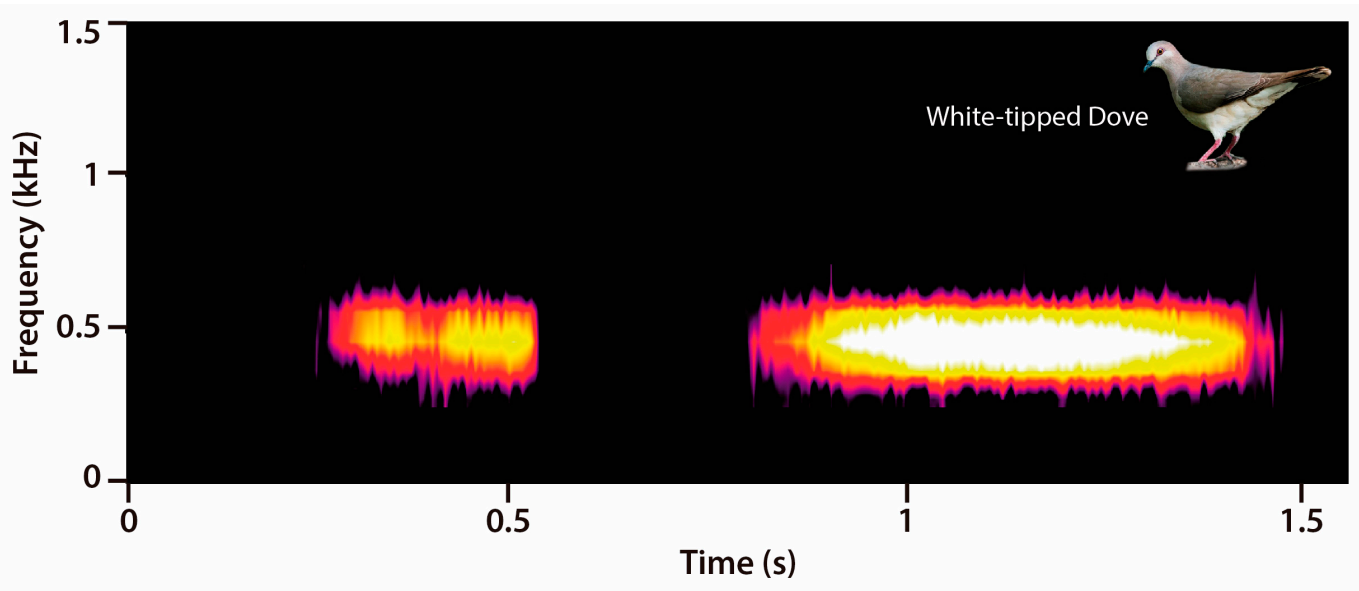

Figure 1. Sonogram of a typical call of the white-tipped dove recorded in the Brazilian Pantanal, showing the two syllables.

In this study, we monitored the vocal behavior of the white-tipped dove over an annual cycle at three sites in the Brazilian Pantanal with an aim to improve our knowledge regarding the vocal behavior of tropical non-passerines. We aimed to (1) evaluate the effectiveness of passive acoustic monitoring as a tool for the study of the shy white-tipped dove; (2) describe and analyze the diel and seasonal patterns of vocal behavior of the species to gain insights into the ecology of the white-tipped dove, and identify the periods (hours and months) with the highest vocal activity; (3) assess the relationship between vocal activity of the white-tipped dove and weather conditions; and (4) estimate the minimum number of recording days required for obtaining a vocal activity rate (VAR) value with low error. The VAR, defined as the number of bird vocalizations detected per unit time of recording, is a soundscape index whose basic assumption is that bird VAR is density-dependent, and therefore, changes in the VAR should be related with changes in bird abundance (e.g., [35-37]). Therefore, the VAR can be used to predict bird abundance around sound recorders (see [26]), but also for monitoring population changes at a long temporal scale (see application in [38]). However, there is very limited information about the minimum number of days that recorders need to be deployed in the field for recording a reliable VAR [39], and thus, we aimed to provide new insights into this issue. Our results about the utility of passive acoustic monitoring, coupled with automated signal recognition software, might be used to guide future studies with critically endangered doves with a similar call structure, such as the blue-eyed ground dove (Columbina cyanopis) [40].

\section{Materials and Methods}

\subsection{Study Area}

Our study was carried out in the northeastern part of the Brazilian Pantanal close to SESC Pantanal (Poconé municipality, Mato Grosso, Brazil; $16^{\circ} 30^{\prime} \mathrm{S}, 56^{\circ} 25^{\prime} \mathrm{W}$; Supplemental Figure S1). The surveyed area comprised three acoustic monitoring stations located near the Cuiabá River, a main tributary of the Paraguay River. The study area is a seasonal floodplain, which is inundated from October to April due to flooding of the Paraguay River. The vegetation is dominated by savannas and different forest formations [41]. A detailed description of the plant community in the study area and the effect of flood seasonality on the local avian community can be found in [42]. The regional climate is tropical and humid, with average annual temperatures around $24^{\circ} \mathrm{C}$ and mean annual rainfall ranging from 1000 to $1500 \mathrm{~mm}$.

\subsection{Acoustic Monitoring}

The three surveyed acoustic monitoring stations were separated by 1300 and $2200 \mathrm{~m}$ (Supplemental Figure S1). One Song Meter SM2 recorder (Wildlife Acoustics, www.wildlifeacoustics.com) was 
deployed at each acoustic monitoring station and operated daily from 8 June 2015 to 16 June 2016. The recorders were programmed to record (.wav format and in stereo) the first $15 \mathrm{~min}$ of each hour in $24 / 7$ mode with a sampling rate of $48 \mathrm{kHz}$ and a resolution of 16 bits per sample. Recordings were saved on SD memory cards (approximately $250 \mathrm{~h}$ of maximum storing). The devices were powered by four $1.5 \mathrm{~V}$ alkaline batteries (approximately 160-h autonomy) and checked every week to download data and replace the batteries. The threshold distance at which the Song Meter SM2 recorder is able to record bird vocalizations may differ among studies according to monitored species (e.g., as a function of main vocalization frequency) and main habitat surveyed (lower in forested areas, [43]). However, several studies have found that very few bird calls recorded with the Song Meter SM2 recorder are detected beyond $100 \mathrm{~m}$ (see [44] and references therein), with maximum detection ranges for the recorder around $200 \mathrm{~m}[45,46]$. Although we did not have proper data for estimating the distance at which the white-tipped dove call could have been recorded by the Song Meter SM2, we believed that the risk of recording the same individual from two different stations should be very low based on the findings already mentioned (described detection radius for the recorder and working in a forested area) and great distance among sampling stations (minimum of $1300 \mathrm{~m}$ ). A total of 23,916 15-min recordings were collected (8044 in Station A, 8075 in station B, and 8122 in Station C; Supplemental Figure S1).

\subsection{Acoustic Data Analyses}

We only analyzed the left channel of the recordings using the automated signal recognition software of Kaleidoscope Pro 5.1.9h (Wildlife Acoustics, www.wildlifeacoustics.com). Kaleidoscope scans the recordings looking for targeted signals based on the following signal parameters: minimum and maximum frequency ranges $(\mathrm{Hz})$, minimum and maximum times of detection (s), and maximum intersyllable gap (ms). First, we parameterized 97 calls of the white-tipped dove recorded in the Brazilian Pantanal to introduce reliable signal parameters in Kaleidoscope (Figure 1 and Supplemental Table S1). White-tipped dove calls were parameterized from spectrograms using Raven Pro 1.5 [47]. The signal parameters introduced in Kaleidoscope were the following: minimum and maximum frequencies (100 and $1000 \mathrm{~Hz}$, respectively), minimum and maximum lengths of detection ( 0.5 and $2 \mathrm{~s}$, respectively, to detect overlapping individuals), and maximum inter-syllable gap ( $0.4 \mathrm{~s})$. The maximum intersyllable gap is defined as the maximum allowable distance between syllables of the same vocalization; therefore, syllables separated by less than $0.4 \mathrm{~s}$ were considered for our study to be part of the same call. We used this value to identify as a single call the two syllables of the call of the white-tipped dove. Nonetheless, the employed parameter allowed us to identify the second syllable, which is the most constant and predominant one [29,32], even if the first syllable was not uttered or was emitted at a low intensity. In this first step, Kaleidoscope scanned the recordings and detected all candidate sounds within the introduced signal parameters.

In the second step, we used the cluster analysis function of Kaleidoscope. Kaleidoscope automatically estimates the discrete cosine transform coefficients (DCTs) of the spectrum of those candidate sounds that fitted within the signal parameters introduced. A Hidden Markov model is built from the vector of the DCTs of each candidate sound, and the vectors are automatically clustered using K-means clustering. Candidate sounds are categorized into clusters (groups of similar candidate sounds). Vocalizations are moved to existing clusters if they are similar to existing clusters, while new clusters are formed if candidate sounds are more different than the defined "maximum distance from the cluster center to include outputs" (see below). Candidate vocalizations are also sorted within clusters according to similitude. Thus, most of the candidate sounds of each cluster are the same sound type, and the first sounds of each cluster can be considered as the most representative of the cluster. We fixed the parameter "maximum distance from cluster center to include outputs" to the maximum value (2.0) since we aimed to identify as much white-tipped dove calls as possible. This parameter varies from 0 to 2 and has a great impact on the number of detected signals, with larger values resulting in a large number of detected signals. Nonetheless, the number of false positives (misclassified signals) is also increased when using large values (see quantitative analyses in [12]). 
In the last step, each cluster created by Kaleidoscope was named as "white-tipped dove" or "other sounds" according to whether a call of the white-tipped dove was found within the first 50 candidate sounds of each cluster. Candidate sounds within the cluster "other sounds" were not checked and were excluded from the study, while every candidate sound of the cluster "white-tipped dove" was visually and/or acoustically checked by the same observer (CPG), to remove false positives from the database. Additionally, we evaluated the effectiveness of the cluster analysis function applied by Kaleidoscope Pro (recognizer hereafter). We estimated the precision of the recognizer, which is a common index of recognizer performance defined as the number of true positives divided by the total number of detected signals [48]. Here, we estimated the precision by dividing the total number of white-tipped dove calls detected by the total number of candidate sounds within the clusters labeled as "white-tipped dove" (see similar approximation in [18]). Additionally, we calculated the recall rate of the recognizer, defined as the proportion of target species vocalizations detected by the recognizer [48]. This index was estimated by dividing the total number of white-tipped dove calls automatically detected by the software Kaleidoscope by the total number of calls of the dove in the selected dataset $[18,48]$. The total number of calls within each recording was always checked by the same observer (CPG) by visually and acoustically checking 180 recordings. We checked a total of 108 15-min recordings with the presence of the species, according to Kaleidoscope (three recordings per station and month), and 72 recordings randomly selected among those recorded between 06:00 and 09:00, when the vocal activity of the species reached its maximum (see results, two recordings per site and month). Recordings were reviewed blinded with respect to date, site, and number of calls detected by Kaleidoscope.

\subsection{Weather Data}

We collected weather data from a meteorological station within the study area (Supplemental Figure S1). The following weather data were collected during the study period: daily mean air temperature $\left({ }^{\circ} \mathrm{C}\right)$, daily relative air humidity $(\%)$, and daily rainfall $(\mathrm{mm})$. We checked that the three weather variables included in the analyses had low collinearity (maximum collinearity was 0.39 between daily mean air temperature and daily relative air humidity [49]).

\subsection{Statistical Analyses}

In order to determine the hours and the months with significantly higher and lower vocal activity of the white-tipped dove, we fitted a generalized linear mixed model (GLMM). The GLMM (Gaussian error structure) was fitted using the mean number of calls detected per hour (log-10 transformed) during each month as the response variable, recording hour and month were introduced as factors, and station (three categorical levels) was used as the random factor to control for intersite variations. We used the mean number of calls detected per hour in each month rather than the total number of calls detected per hour in each month to control for the variable number of recording days per month (e.g., the study ended on 16 June 2016). We used Tukey's post hoc tests to identify those hours and months with significantly higher vocal activity.

We fitted the GLMM (Gaussian error structure) to assess the impact of weather conditions on the vocal activity of the white-tipped dove. The daily number of calls detected was used as the response variable; weather variables (daily mean air temperature, daily relative air humidity, and daily rainfall) were included in the model as predictors; and station (three categorical levels) was also included as the random factor to control for variations among sites. We focused the analyses on the period between 1 May 2016 and 16 June 2016, the two months with significantly higher vocal activity of the species during the study period (see results). For each GLMM, we evaluated model performance by plotting standardized residuals versus fitted variables, histogram of residuals, and normal Q-Q plots.

We also estimated the minimum number of recording days required for estimating a VAR of the white-tipped dove with low error. To do this, we created curves of the coefficient of variation (CV) [50] of the VAR of the white-tipped dove as a function of monitoring days. This analysis was carried out by considering all possible combinations of recording days during the last fortnight of 
May (15-31 May 2016), which was the fortnight with the maximum calling activity of the species. We established that the CV should be lower than $20 \%$ to consider the VAR reliable [39,51]. Statistical analyses were run in R 3.6.2 [52], using the specialized packages "multcomp" [53] for post hoc comparison tests and "gtools" [54] for estimating all possible combinations from 1 to 15 monitoring days. The level of significance was $p<0.05$.

\section{Results}

The Kaleidoscope output reported a total of 657,293 candidate sounds that matched the signal parameters, of which 338,045 were within the cluster "other sounds". The precision of the recognizer was $87.2 \%$ since 278,372 calls of the white-tipped dove were detected among the 319,248 candidate sounds within the "white-tipped dove" cluster. Most of the misclassified sounds in the "white-tipped dove" cluster were bird vocalizations of similar frequencies and with a similar call duration to that of the white-tipped dove, such as the great-horned owl (Bubo virginianus) and the Chaco Chachalaca (Ortalis canicollis), but some cow (Bos taurus) calls were also misclassified. The recall rate of the recognizer was $78.5 \%$ (7586 calls detected among the 9659 annotated calls in the 180 recordings of the validation dataset). The species was detected at the three acoustic monitoring stations, with a variable number of calls per station between 60,681 and 112,877 .

\subsection{Diel Activity Pattern}

The vocal activity of the white-tipped dove was almost restricted to the daytime with very few calls recorded at night (Figure 2 and Supplemental Table S2). The diel pattern of vocal activity showed a bimodal pattern. The first, and the highest, peak of vocal activity occurred after sunrise and extended from 06:00 to 09:00 (Figure 2, mean of 28.9 calls detected per recording between 06:00 and 09:00). After sunrise, the vocal activity decreased until prior to sunset, when a second and lower peak of vocal activity occurred (Figure 2, mean of 18.9 calls detected per recording between 16:00 and 17:00). The GLMM showed that the white-tipped dove exhibited the highest vocal activity at 08:00 (Table 1, mean of 31.1 calls per recording at 08:00), but it did not differ from the vocal activity that occurred at 06:00 and 07:00, while the significant lowest vocal activity occurred between 19:00 and 04:00, when vocal activity was zero or very reduced (see Supplemental Figure S2 for Tukey's post hoc comparisons).

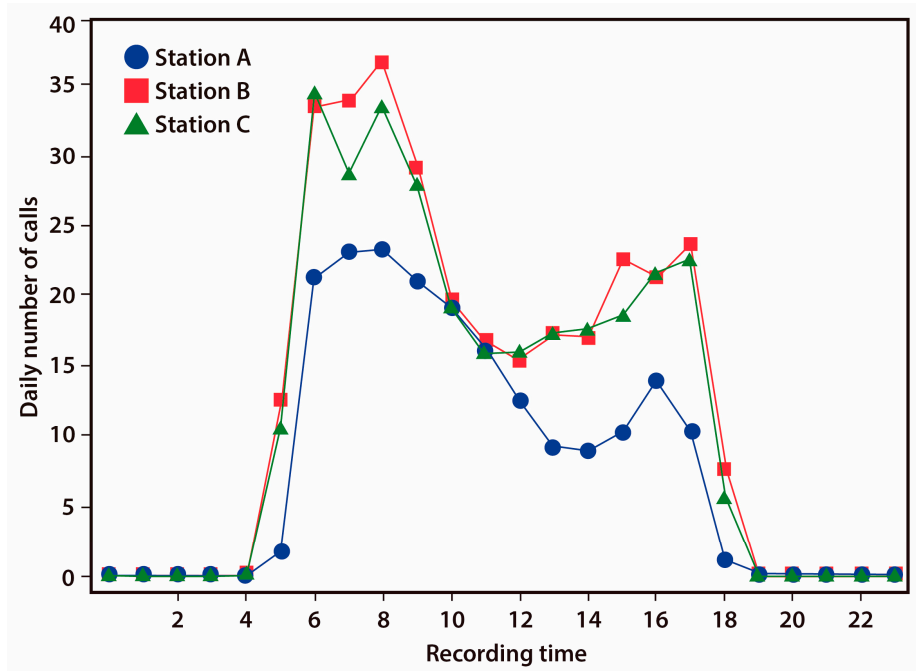

Figure 2. Diel vocal activity pattern of the white-tipped dove in the Brazilian Pantanal. Vocal activity was monitored using autonomous sound recorders from 8 June 2015 to 16 June 2016 at three acoustic monitoring stations. The diel pattern is expressed as the mean number of calls detected during each recording hour (UTC-4) per station. 
Table 1. Results of variance partitioning analysis performed to test the effect of recording time and month on the vocal activity of the white-tipped dove in the Brazilian Pantanal. The effect of recording hour and month on the vocal activity of the species was assessed with a generalized linear mixed model using the mean number of calls detected per recording time during each month as the response variable, recording hour and month as factors, and station as the random factor. Vocal activity was monitored using autonomous recording units from 8 June 2015 to 16 June 2016 at three acoustic monitoring stations. $\mathrm{Sq}=$ squares. $\mathrm{df}=$ degrees of freedom. Den $\mathrm{df}=$ Denominator degrees of freedom.

\begin{tabular}{ccccccc}
\hline Variable & Sum Sq & Mean Sq & df & Den df & F & $p$ \\
\hline Hour & 261.60 & 11.38 & 12 & 898 & 104.63 & $<0.0001$ \\
Month & 31.42 & 2.62 & 23 & 898 & 24.09 & $<0.0001$ \\
\hline
\end{tabular}

\subsection{Seasonal Activity Pattern}

The white-tipped dove was vocally active over the annual cycle. The species was detected on $97.5 \%$ of the monitored days. The vocal activity of the species showed clear seasonality and reached its maximum value during the month of May, followed by the months of June 2015 and June 2016, with a mean value of 22.8 calls detected per recording during these months (Figure 3 and Supplemental Table S3). In contrast, the vocal activity of the species was low from January to February (mean of 1-5 calls detected per recording, Figure 3). According to the GLMM, the vocal activity of the species significantly differed among the monitored months (Table 2), with May being the month with the greatest vocal activity and February with the lowest vocal activity (see Supplemental Figure S3 for Tukey's post hoc results).

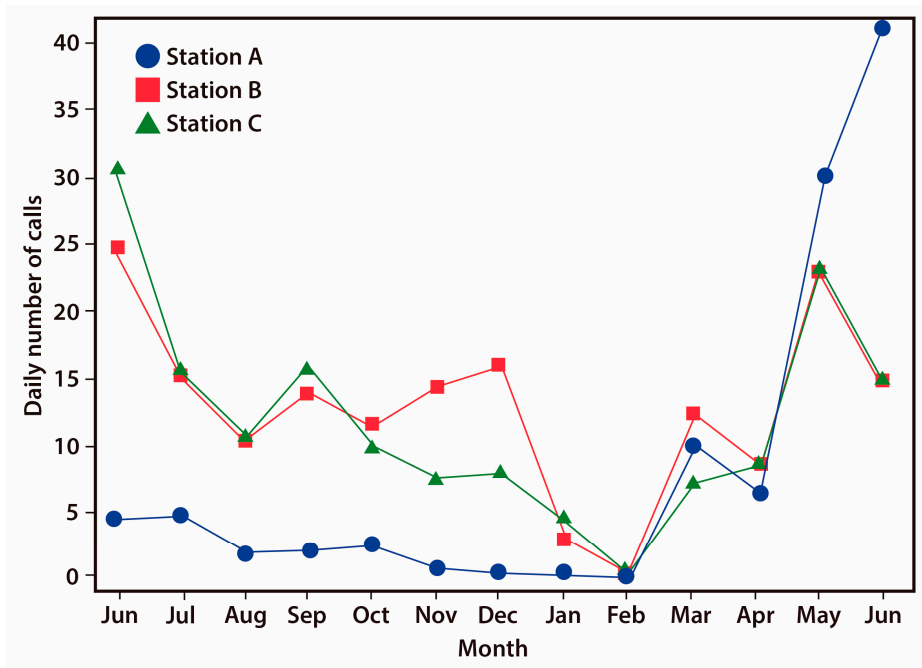

Figure 3. Pattern of seasonal vocal activity of the white-tipped dove in the Brazilian Pantanal. Vocal activity was recorded using autonomous recording units from 8 June 2015 to 16 May 2016 at three acoustic monitoring stations. The seasonal pattern is expressed as the mean number of calls detected per recording at each station and month. 
Table 2. Results of the generalized linear mixed model analysis used to test the effects of weather conditions on the vocal activity of the white-tipped dove in the Brazilian Pantanal. The daily number of calls detected was used as the response variable, weather conditions were predictors, and station was included as the random factor. Vocal activity was monitored using autonomous recording units from 1 May 2016 to 16 June 2016 at three acoustic monitoring stations.

\begin{tabular}{ccccc}
\hline Variable & Estimate & Std. Error & $\boldsymbol{t}$-Value & $\boldsymbol{p}$ \\
\hline Intercept & -587.80 & 513.41 & -1.145 & 0.254 \\
Mean air temperature $\left({ }^{\circ} \mathrm{C}\right)$ & -11.71 & 8.99 & -1.302 & 0.195 \\
Air humidity $(\%)$ & 16.74 & 6.79 & 2.466 & 0.015 \\
Daily rainfall & 2.12 & 4.23 & 0.500 & 0.618 \\
\hline
\end{tabular}

\subsection{Environmental Predictors}

The vocal activity of the white-tipped dove during the analyzed period (1 May-16 June 2016) was significantly associated with the daily relative air humidity (Table 2); the species produced the largest number of calls on days with high relative air humidity (Figure 4). However, the vocal activity was not significantly associated with the daily mean air temperature or daily rainfall (Table 2).

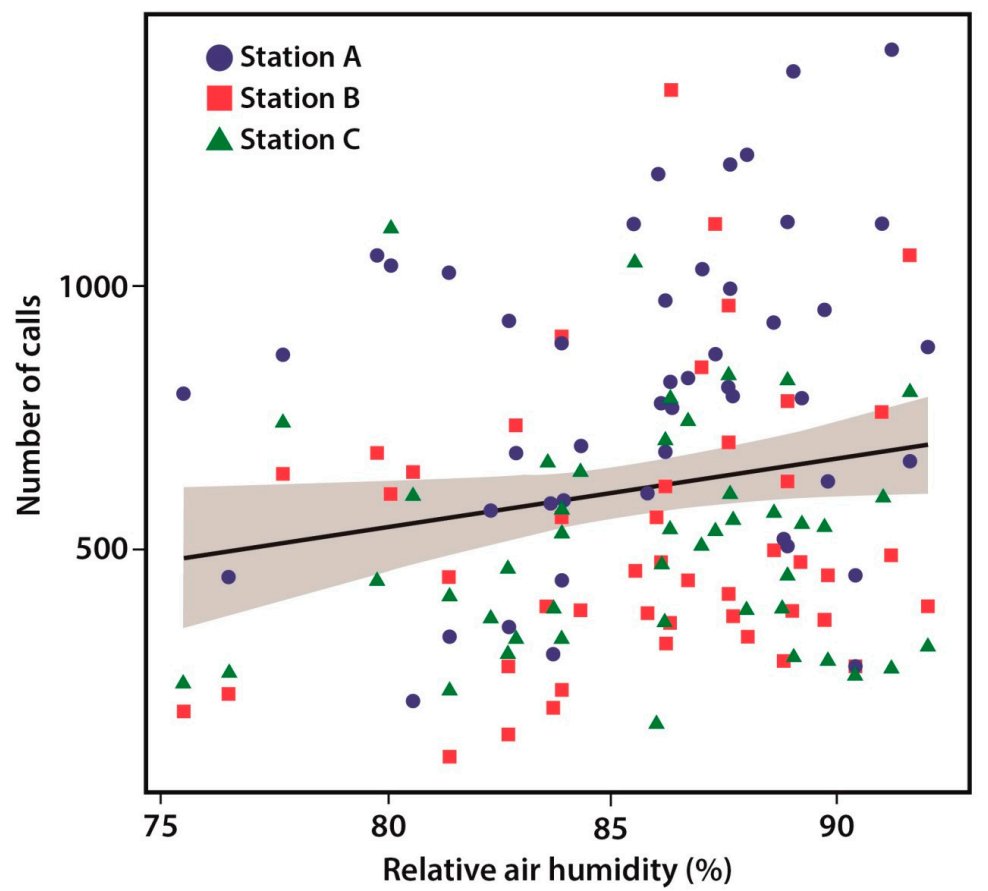

Figure 4. Scatterplot showing the variation in the daily vocal activity of the white-tipped dove as a function of the daily relative air humidity during the period of 1 May-16 June 2016. Vocal activity was monitored using autonomous sound recorders at three acoustic monitoring stations, with data from the different stations represented by different symbols. The line of the linear regression between daily vocal activity and relative air humidity is shown in black, and 95\% confidence intervals are shown in gray.

\subsection{Monitoring Protocol}

The VAR of the white-tipped dove decreased sharply with the increasing number of monitoring days (Figure 5). The declining pattern found among the three monitored stations was similar, and we estimated that three monitoring days was the minimum survey effort required to obtain a VAR with a CV $<20 \%$. This CV could decrease to values around $10 \%$ when recording during seven consecutive days (Figure 5). 


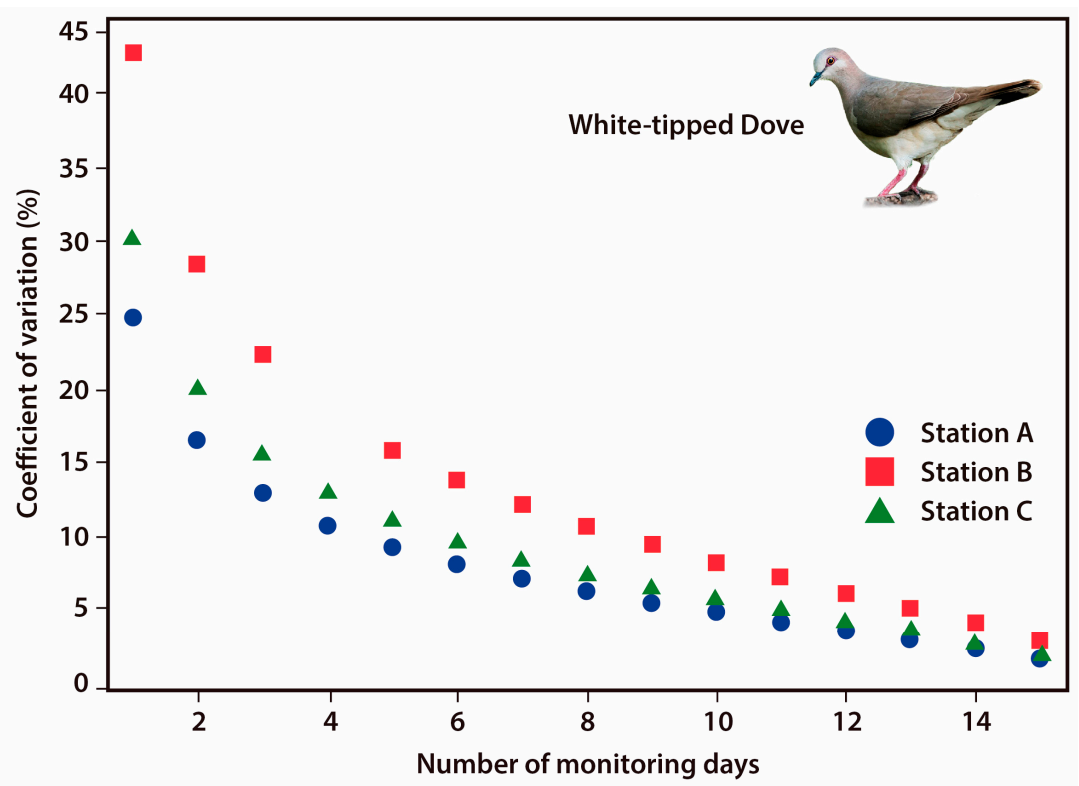

Figure 5. Coefficient of variation (\%) of the daily vocal activity rate of the white-tipped dove as a function of monitoring days. Calling activity was recorded using autonomous sound recorders during the last fortnight of May in the Brazilian Pantanal at three acoustic monitoring stations. The different symbols show the coefficients of variation of the vocal activity rate at the three acoustic monitoring stations monitored.

\section{Discussion}

In this study, we monitored the vocal behavior of the white-tipped dove over a complete annual cycle and validated the use of acoustic monitoring for future surveys aiming to monitor this species. Vocal behavior of the white-tipped dove varied with the time of day, time of season, and air humidity. The diel pattern of vocal activity of the species was almost completely restricted to the daytime, with no calls detected between 19:00 and 03:00. This time period during which the species was vocally silent was between sunset and sunrise throughout the study period. The higher rate of vocal activity was reached during the first three hours after sunrise (06:00-08:00) and the two hours prior to sunset (16:00-17:00). This bimodal pattern of calling activity at the daily scale is in agreement with the pattern described for other members of Columbidae, such as the pale-vented pigeon (Patagioenas cayennensis) and the Scaled Pigeon (Patagioenas speciosa) [55]. The first three hours after sunrise were also defined as "a time of high calling activity" for the white-tipped dove in south Texas [56]. However, in Costa Rica, the species was declared to be most vocally active in the warmer parts of the day, toward noon and in the early afternoon [31]. These results might be related to the existence of regional differences in the diel pattern of vocal activity of the species, but are more likely due to the different methodologies employed. However, as Skutch [31] did not provide any description of how vocal activity was measured, it is not possible to clarify this issue. We would like to highlight that our data was collected on a reduced number of acoustic monitoring stations and thus some of our generalizations may require further research on a larger number of sites to obtain more robust conclusions. Similarly, further research should try to consider the number of birds vocalizing around recorders and territory size of the monitored species as covariates to refine our approach and increase our understanding about vocal behavior of non-passerine tropical birds.

The white-tipped dove vocalized daily throughout the monitored annual cycle, but the vocal activity showed clear seasonality. According to the detected seasonal pattern of vocal activity, the breeding season of the species in the Brazilian Pantanal seems to occurs from April onwards, when the flooded season usually ends [41,42]. The proposed breeding season is in agreement with anecdotal records of active nests found in Brazil (March-May [29]) and with the nesting ecology reported for 
Costa Rica, where most nests were found after March [31]. It is known that, in Costa Rica, Surinam, and Argentina, the white-tipped dove is able to breed throughout the year [29,31,32]. The seasonal character of the study area, a floodplain wetland subject to a monomodal inundation cycle, may force the white-tipped dove to breed during the available time window between when one flooded season ends and the next flood pulse starts. Nonetheless, further research is needed to evaluate whether the nesting ecology of the species is influenced by the flood dynamics of the Brazilian Pantanal. We cannot rule out the possibility that the low vocal activity found during January and February may be related to a decrease in the amount of time that individuals spent vocalizing near the sound recorders during the wet period, when the inundated area becomes restrictive to foraging [42,57]. Indeed, in the Pantanal, the percentage of trees producing flowers and mature fruits reaches its minimum value during the peak of the wet season [58]. Therefore, lower food availability and flooding during the wet season may have forced the white-tipped dove to perform larger movements when looking for food and thus to spend less time singing around the recorders. The lower vocal activity during the wet season might be also related to reduced motivation for vocalizing display during the non-mating season, as demonstrated in several tropical birds (e.g., $[10,51,59,60])$

The vocal activity of the white-tipped dove was positively associated with the relative air humidity. Our results agree with previous studies that found higher vocal activity during days with greater air humidity in both passerines and non-passerines (e.g., [17,61,62]). The increase in vocal activity at higher humidities might be related to more efficient sound transmission under these circumstances, although this effect should be very small for sounds below $1000 \mathrm{~Hz}$, such as the white-tipped dove call [63]. In agreement with what has been proposed for other tropical bird species [17,62], the increase in vocal activity under more humid conditions could be related to a higher foraging efficiency, and therefore more energy and time available for calling, due to an increase in the availability of invertebrates on more humid days [64]. Bird vocal activity on rainy days could decrease since vocalization under these circumstances can be inefficient due to the masking effect of rain $[65,66]$ or because individuals may search for shelter [67]. However, we did not find any relationship between the vocal activity of the white-tipped dove and daily rainfall. The number of rainy days during the analyzed period (1 May-16 June) was very low (only five days had accumulated rainfall higher than $1 \mathrm{~mm}$ ), which may have reduced our ability to find a relationship between daily rainfall and the vocal activity of the white-tipped dove, in contrast to what has been found in several other non-passerines (e.g., [66,68,69]). Cooler temperatures may increase sound transmission [70]. Indeed, several studies have found greater vocal activity in non-passerines at cooler temperatures (e.g., $[17,62,66,71])$, including previous research on the ferruginous pygmy-owl (Glaucidium brasilianum) in the Brazilian Pantanal [51]. Nonetheless, the vocal activity of the white-tipped dove was not significantly associated with mean air temperature. The differences found among studies might be related to differences in the daily patterns of activity among species, since the white-tipped dove showed a more constant pattern than the ferruginous pygmy-owl, whose vocal activity was concentrated at dawn, when the air temperature reaches the lowest values of the day.

Acoustic monitoring, coupled with the cluster analysis function of Kaleidoscope Pro, was useful in studying the vocal behavior of the white-tipped dove. The recall rate $(78.5 \%)$ of the recognizer can be considered high when compared with the values obtained in previous studies (e.g., [72-74]) and is in agreement with that found in a prior study that also used the Kaleidoscope for monitoring the vocal behavior of two potoos (Nyctibius griseus and Nyctibius grandis) in the study area (the recall rate ranged between $74 \%$ and $85 \%$, [18]). Most of the white-tipped dove vocalizations not detected by Kaleidoscope were attributed to calls uttered by the species presumably from long distances according to the low sound level of some of the calls annotated in the validation dataset (pers. obs). In these cases, we were able to detect these calls on the spectrogram viewer or when hearing the recordings, but their pattern might have been too weak to be detected by Kaleidoscope. The precision of the recognizer was high $(87 \%)$, and although a lower value should not have influenced our results, since every event was verified, it would have precluded the use of the technique in future surveys due to the very large 
number of candidate sounds that need to be verified. Previous studies found a much lower precision recognizer when using the same approach with the two potoos $(9 \%-29 \%,[18])$. The high vocal activity and simple call of the white-tipped dove may have facilitated the creation of specific clusters for the species through the cluster analysis function, which, combined with the narrow frequency of the call of the species, may have reduced the number of misclassified sounds within the "white-tipped dove" cluster and partly explain the high precision found in our study.

We estimated that three monitoring days were sufficient for detecting a reliable VAR of the species $(\mathrm{CV}<20 \%)$. We are aware that this value was estimated on the basis of our recording schedule (15 mins per hour in 24/mode), but future studies aiming to monitor the white-tipped dove should not record during the night, since this species was never detected between 19:00 and 03:00. Although we had no data to assess the relationship between VAR and white-tipped dove abundance around recorders, we believe that our assessment of the number of days required for estimating a reliable VAR might be helpful for future studies aiming to monitor that or other bird species, due to reduced number of studies dealing with this issue. However, to estimate the minimum effort required to obtain a reliable VAR should be a prerequisite for any future monitoring program aiming to obtain robust conclusions. To the best of our knowledge, only two previous studies have evaluated the number of monitoring days needed to estimate a reliable VAR for terrestrial bird species, which followed the same approach that we employed. In both cases, the authors estimated a minimum number of nine monitoring days to obtain a low-error VAR $(\mathrm{CV}<20 \%)$ for the monitored species (see $[39,51])$. Our results suggested that the VAR of the white-tipped dove was very consistent among days and that this index might be useful for evaluating population changes over time and space [26]. It could also be used as an index to evaluate future habitat changes in the Brazilian Pantanal [75] due to the common and forested character of the white-tipped dove habitat.

Our study increases our knowledge regarding the vocal behavior of tropical non-passerines, in addition to the seasonality of the Pantanal, the world's largest wetland [76], and the relationship between tropical bird vocal activity and weather conditions. More specifically, our results suggest that passive acoustic monitoring, coupled with the cluster analysis function of Kaleidoscope, is an effective technique to study the vocal behavior of the white-tipped dove. The use of autonomous recording units should be evaluated to monitor the current distribution and population trends of critically endangered doves, such as the purple-winged ground dove (Claravis geoffroyi [77]) and the blue-eyed ground dove [40].

Supplementary Materials: The following are available online at http://www.mdpi.com/1424-2818/12/10/402/s1. Figure S1: Location of the three acoustic monitoring stations and the weather station in the Brazilian Pantanal (Pantanal of Mato Grosso, Poconé municipality, Mato Grosso, Brazil). The inset shows the location of the study area (red square) and the Brazilian Pantanal. Scale bar: $1 \mathrm{~km}$. Figure S2: Plot showing the results of Tukey's post hoc test for the factor of Hour. Different letters indicate significant differences in the vocal activity of the White-tipped Dove among hours according to Tukey's test. Figure S3: Plot showing the results of Tukey's post hoc test for the factor of Month. Different letters indicate significant differences in the vocal activity of the White-tipped Dove among months according to Tukey's test. Table S1: Mean \pm SD (and range) of the acoustic parameters of the call of the White-tipped Dove in the Brazilian Pantanal. A total of 97 calls from the three monitored acoustic stations were measured. Recordings were collected using a Song Meter SM2 recorder (Wildlife Acoustics), and call measurements were performed using Raven Pro 1.5. Table S2: Number of White-tipped Dove calls detected per hour at three monitoring stations in the Brazilian Pantanal. The total number and percentage of calls detected per hour, with respect to the total number of calls, are also shown. Vocal activity was monitored with acoustic monitoring from 8 June 2015 to 16 June 2016 at three acoustic monitoring stations. Table S3: Number of White-tipped Dove calls detected per month and station in the Brazilian Pantanal. The total number and percentage of calls detected per month, with respect to the total number of calls, are also shown. Vocal activity was monitored with acoustic monitoring from 8 June 2015 to 16 June 2016 at three acoustic monitoring stations.

Author Contributions: C.P.-G. and K.-L.S. conceived the idea, design, and experiment (supervised research, formulated question or hypothesis); K.-L.S. performed the experiments (collected data and conducted the research); C.P.-G. and K.-L.S. wrote the paper (or substantially edited the paper); C.P.-G. developed or designed methods; C.P.-G. analyzed the data; and K.-L.S. contributed substantial materials, resources, or funding. All authors have read and agreed to the published version of the manuscript. 
Funding: This research was funded by Coordenação de Aperfeiçoamento de Pessoal de Nivel Superior-Brasil (CAPES), Finance Code 01; Instituto Nacional de Ciência e Tecnologia em Áreas Úmidas (INAU/UFMT/CNPq); Centro de Pesquisa do Pantanal (CPP); and Brehm Funds for International Bird Conservation (BF), Bonn, Germany.

Acknowledgments: We thank SESC Pantanal, Mato Grosso, for permission to conduct research on the property and logistical help with our fieldwork. We also thank Ana Silvia Tissiani and Jose María de la Peña for their technical support. We wish to thank Javier Seoane for his valuable comments to improve the statistical analyses. This study is part of the biodiversity monitoring project "Sounds of the Pantanal-The Pantanal Automated Acoustic Biodiversity Monitoring Program" of INAU, Cuiabá, Mato Grosso, Brazil, which was conducted under SISBIO permit no. 39095 (KLS).

Conflicts of Interest: The authors declare no conflict of interest.

\section{References}

1. Brewster, W. Notes and song-flight of the Woodcock (Philohela minor). Auk 1894, 11, 291-298. [CrossRef]

2. Hawkins, C.J. Sexual selection and bird song. Auk 1918, 35, 421-437.

3. Marler, P. Bird calls: Their potential for behavioral neurobiology. Ann. Acad. Sci. 2004, 1016, 31-44. [CrossRef]

4. Farnsworth, A. Flight calls and their value for future ornithological studies and conservation research. Auk 2005, 122, 733-746. [CrossRef]

5. Gil, D.; Llusia, D. The bird dawn chorus revisited. In Coding Strategies in Vertebrate Acoustic Communication. Animal Signals and Communication; Aubin, T., Mathevon, N., Eds.; Springer: Cham, Switzerland, 2020; Volume 7, pp. 45-90.

6. Amrhein, V.; Korner, P.; Naguib, M. Nocturnal and diurnal singing activity in the nightingale: Correlations with mating status and breeding cycle. Anim. Behav. 2002, 64, 939-944. [CrossRef]

7. Catchpole, C.K.; Slater, P.J. Bird Song: Biological Themes and Variations, 2nd ed.; Cambridge University Press: Cambridge, UK, 2008.

8. Barker, N.K. Bird song structure and transmission in the Neotropics: Trends, methods and future directions. Ornitol. Neotrop. 2008, 19, 175-199.

9. Riebel KOdom, K.J.; Langmore, N.E.; Hall, M.L. New insights from female bird song: Towards an integrated approach to studying male and female communication roles. Biol. Lett. 2019, 15, 20190059. [CrossRef]

10. Topp, S.M.; Mennill, D.J. Seasonal variation in the duetting behaviour of Rufous-and-white Wrens (Thryothorus rufalbus). Behav. Ecol. Sociobiol. 2008, 62, 1107-1117. [CrossRef]

11. Jahn, O.; Ganchev, T.D.; Marques, M.I.; Schuchmann, K.L. Automated sound recognition provides insights into the behavioral ecology of a tropical bird. PLOS ONE 2017, 12, e0169041. [CrossRef]

12. Pérez-Granados, C.; Schuchmann, K.L.; Marques, M.I. Vocal behavior of the Undulated Tinamou (Crypturellus undulatus) over an annual cycle in the Brazilian Pantanal: New ecological information. Biotropica 2020, 52, 165-171. [CrossRef]

13. Kirschel, A.N.; Blumstein, D.T.; Cohen, R.E.; Buermann, W.; Smith, T.B.; Slabbekoorn, H. Birdsong tuned to the environment: Green Hylia song varies with elevation, tree cover, and noise. Behav. Ecol. 2009, 20, 1089-1095. [CrossRef]

14. Sosa-López, J.R.; Mennill, D.J. The vocal behavior of the Brown-throated Wren (Troglodytes brunneicollis): Song structure, repertoires, sharing, syntax, and diel variation. J. Ornithol. 2014, 155, 435-446. [CrossRef]

15. Sandoval, L.; Méndez, C.; Mennill, D.J. Vocal behaviour of White-eared Ground-Sparrows (Melozone leucotis) during the breeding season: Repertoires, diel variation, behavioural contexts, and individual distinctiveness. J. Ornithol. 2016, 157, 1-12. [CrossRef]

16. Baldo, S.; Mennill, D.J. Vocal behavior of Great Curassows, a vulnerable Neotropical bird. J. Field Ornithol. 2011, 82, 249-258. [CrossRef]

17. Braga, A.C.R.; Motta-Junior, J.C. Weather conditions and moon phase influence on Tropical Screech Owl and Burrowing Owl detection by playback. Ardea 2009, 97, 395-401. [CrossRef]

18. Pérez-Granados, C.; Schuchmann, K.L. Monitoring the annual vocal activity of two enigmatic nocturnal Neotropical birds: The Common Potoo (Nyctibius griseus) and the Great Potoo (Nyctibius grandis). J. Ornithol. 2020, 161, 1129-1141. [CrossRef] 
19. Pérez-Granados, C.; Schuchmann, K.L.; Marques, M.I. Vocal activity of the Ferruginous Pygmy-Owl (Glaucidium brasilianum) is strongly correlated with moon phase and nocturnal temperature. Ethol. Ecol. Evol. 2020. [CrossRef]

20. Hackett, S.J.; Kimball, R.; Reddy, S.; Bowie, R.C. A phylogenomic study of birds reveals their evolutionary history. Science 2008, 320, 1763-1768. [CrossRef]

21. Odom, K.; Mennill, D. Vocal duets in a nonpasserine: An examination of territory defence and neighbour-stranger discrimination in a neighbourhood of Barred Owls. Behaviour 2010, 147, 619-639.

22. Sugai, L.S.M.; Silva, T.S.F.; Ribeiro, J.W., Jr.; Llusia, D. Terrestrial passive acoustic monitoring: Review and perspectives. BioScience 2019, 69, 15-25. [CrossRef]

23. Marques, T.A.; Thomas, L.; Martin, S.W.; Mellinger, D.K.; Ward, J.A.; Moretti, D.J.; Harris, D.; Tyack, P.L. Estimating animal population density using passive acoustics. Biol. Rev. 2013, 88, 287-309. [CrossRef] [PubMed]

24. Van Wilgenburg, S.L.; Sólymos, P.; Kardynal, K.J.; Frey, M.D. Paired sampling standardizes point count data from humans and acoustic recorders. Avian Conserv. Ecol. 2017, 12, 13. [CrossRef]

25. Bombaci, S.P.L.; Pejchar, L. Using paired acoustic sampling to enhance population monitoring of New Zealand's forest birds. J. Ecol. 2019, 43, 3356. [CrossRef]

26. Oppel, S.; Hervias, S.; Oliveira, N.; Pipa, T.; Silva, C.; Geraldes, P.; Goh, M.; Immler, E.; McKown, M. Estimating population size of a nocturnal burrow-nesting seabird using acoustic monitoring and habitat mapping. Nat. Conserv. 2014, 7, 1-13. [CrossRef]

27. Deichmann, J.L.; Hernandez-Serna, A.; Campos-Cerqueira, M.; Aide, T.M. Soundscape analysis and acoustic monitoring document impacts of natural gas exploration on biodiversity in a tropical forest. Ecol. Indic. 2017, 74, 39-48. [CrossRef]

28. Schroeder, K.M.; Mcrae, S.B. Automated auditory detection of a rare, secretive marsh bird with infrequent and acoustically indistinct vocalisations. Ibis 2020, 162, 1033-1046. [CrossRef]

29. Baptista, L.F.; Trail, P.W.; Horblit, H.M. White-tipped Dove (Leptotila verreauxi). In Handbook of the Birds of the World Alive; Del Hoyo, J., Elliott, A., Sargatal, J., Christie, D.A., de Juana, E., Eds.; Lynx Edicions: Barcelona, Spain, 2020.

30. Bird Life International. Leptotila verreauxi. In IUCN Red List of Threatened Species; Bird Life International: Cambridge, UK, 2016.

31. Skutch, A.F. Life histories of Central American pigeons. Wilson Bull. 1964, 76, 211-247.

32. Fraga, R.M. Vocal and reproductive behavior of Leptotila verreauxi in Lobos, Buenos Aires, Argentina. Hornero 1983, 12, 89-95.

33. Giese, J.C.; Oldenburger, S.L.; Mathewson, H.A.; Schwertner, T.W.; Breeden, J.B. Survival and longevity of a White-tipped Dove (Leptotila verreauxi) population in south Texas. J. Ornithol. 2018, 130, 996-999. [CrossRef]

34. Hall, J.D.; Giese, J.C.; Mathewson, H.A.; Schwertner, T.W.; Oldenburger, S.L.; Breeden, J.B. Parental behavior and attendance patterns of nesting White-tipped Doves (Leptotila verreauxi) in the lower Rio Grande Valley of Texas. Southwest. Nat. 2019, 63, 142-145. [CrossRef]

35. Larkin, R.P.; Evans, W.R.; Diehl, R.H. Nocturnal flight calls of Dickcissels and Doppler radar echoes over south Texas in spring. J. Field Ornithol. 2002, 73, 2-9. [CrossRef]

36. Abrahams, C. Comparison between lek counts and bioacoustic recording for monitoring Western Capercaillie (Tetrao urogallus L.). J. Ornithol. 2019, 19, 685-697. [CrossRef]

37. Pérez-Granados, C.; Bota, G.; Giralt, D.; Barrero, A.; Gómez-Catasús, J.; Bustillo-De La Rosa, D.; Traba, J. Vocal activity rate index: A useful method to infer terrestrial bird abundance with acoustic monitoring. Ibis 2019, 161, 901-907. [CrossRef]

38. Buxton, R.T.; Jones, I.L. Measuring nocturnal seabird activity and status using acoustic recording devices: Applications for island restoration. J. Field Ornithol. 2012, 83, 47-60. [CrossRef]

39. Pérez-Granados, C.; Gómez-Catasús, J.; Bustillo-de la Rosa, D.; Barrero, A.; Reverter, M.; Traba, J. Effort needed to accurately estimate vocal activity rate index using acoustic monitoring: A case study with a dawn-time singing passerine. Ecol. Indic. 2019, 107, 105608. [CrossRef]

40. Bird Life International. Columbina cyanopis. In Red List of Threatened Species; Bird Life International: Cambridge, UK, 2019.

41. Junk, W.J.; Da Cunha, C.N.; Wantzen, K.M.; Petermann, P.; Strüssmann, C.; Marques, M.I.; Adis, J. Biodiversity and its conservation in the Pantanal of Mato Grosso, Brazil. Aquat. Sci. 2006, 68, 278-309. [CrossRef] 
42. De Deus, F.F.; Schuchmann, K.L.; Arieira, J.; de Oliveira Tissiani, A.S.; Marques, M.I. Avian eta diversity in a Neotropical wetland: The effects of flooding and vegetation structure. Wetlands 2020,1-15. [CrossRef]

43. Yip, D.; Leston, L.; Bayne, E.; Sólymos, P.; Grover, A. Experimentally derived detection distances from audio recordings and human observers enable integrated analysis of point count data. Avian Conserv. Ecol. 2017, 12, 11. [CrossRef]

44. Darras, K.; Batáry, P.; Furnas, B.; Celis-Murillo, A.; Van Wilgenburg, S.L.; Mulyani, Y.A.; Tscharntke, T. Comparing the sampling performance of sound recorders versus point counts in bird surveys: A meta-analysis. J. Appl. Ecol. 2018, 55, 2575-2586. [CrossRef]

45. Rempel, R.S.; Francis, C.M.; Robinson, J.N.; Campbell, M. Comparison of audio recording system performance for detecting and monitoring songbirds. J. Field Ornithol. 2013, 84, 86-97. [CrossRef]

46. Pérez-Granados, C.; Bota, G.; Giralt, D.; Albarracín, J.; Traba, J. Cost-effectiveness assessment of five audio recording systems for wildlife monitoring: Differences between recording distances and singing direction. Ardeola 2019, 66, 311-325. [CrossRef]

47. Bioacoustics Research Program Raven Pro. Interactive Sound Analysis Software. Version 1.5. Computer Software. Available online: http://www.birds.cornell.edu/raven (accessed on 3 April 2020).

48. Knight, E.; Hannah, K.; Foley, G.; Scott, C.; Brigham, R.; Bayne, E. Recommendations for acoustic recognizer performance assessment with application to five common automated signal recognition programs. Avian Conserv. Ecol. 2017, 12, 14. [CrossRef]

49. Dormann, C.F.; Elith, J.; Bacher, S.; Buchmann, C.; Carl, G.; Carré, G.; Marquéz, G.R.J.; Gruber, B.; Lafourcade, B.; Leitão, P.J.; et al. Collinearity: A review of methods to deal with it and a simulation study evaluating their performance. Ecography 2013, 36, 27-46. [CrossRef]

50. Reed, G.F.; Lynn, F.; Meade, B.D. Use of coefficient of variation in assessing variability of quantitative assays. Clin. Diagn. Lab. Immunol. 2002, 9, 1235-1239. [CrossRef]

51. Pérez-Granados, C.; Schuchmann, K.L. Illuminating the nightlife of two Neotropical nightjars: Vocal behavior over a year and monitoring recommendations. Ethol. Ecol. Evol. 2020, 32, 466-480. [CrossRef]

52. R Development Core Team. R. A Language and Environment for Statistical Computing; R Foundation for Statistical Computing: Vienna, Austria, 2019.

53. Hothorn, T.; Bretz, F.; Westfall, P. Simultaneous inference in general parametric models. Biom. J. 2008, 50, 346-363. [CrossRef]

54. Warnes, G.R.; Bolker, B.; Lumley, T.; Warnes, M.G.R. Package 'Gtools'. R Package Version 3.8.1; R Foundation for Statistical Computing: Vienna, Austria, 2018; pp. 1-47.

55. Laverde, R.O.; Caycedo-Rosales, P.; Pulgarin, R.P.C.; Cadena, C.D. Bird songs on the shelf: Assessing vocal activity and output using data hidden in sound archives. BioRxiv 2017, 202978. [CrossRef]

56. Boydstun, C.P.; DeYoung, C.A. Distribution and relative abundance of white-tipped doves in South Texas. Southwest. Nat. 1985, 30, 567-571. [CrossRef]

57. De Pinho, J.B.; Aragona, M.; Hakamada, K.Y.P.; Marini, M.A. Migration patterns and seasonal forest use by birds in the Brazilian Pantanal. Bird Conserv. Int. 2017, 27, 371-387. [CrossRef]

58. Ragusa-Netto, J. Flowers, fruits, and the abundance of the Yellow-chevroned Parakeet (Brotogeris chiriri) at a gallery forest in the south Pantanal (Brazil). Braz. J. Biol. 2004, 64, 867-877. [CrossRef]

59. Koloff, J.; Mennill, D.J. Vocal behaviour of Barred Antshrikes, a Neotropical duetting suboscine bird. J. Ornithol. 2013, 154, 51-61. [CrossRef]

60. Demko, A.D.; Mennill, D.J. Rufous-capped Warblers Basileuterus rufifrons show seasonal, temporal and annual variation in song use. Ibis 2019, 161, 481-494. [CrossRef]

61. Hüppop, O.; Hilgerloh, G. Flight call rates of migrating thrushes: Effects of wind conditions, humidity and time of day at an illuminated offshore platform. J. Avian Biol. 2012, 43, 85-90. [CrossRef]

62. Digby, A.; Towsey, M.; Bell, B.D.; Teal, P.D. Temporal and environmental influences on the vocal behaviour of a nocturnal bird. J. Avian Biol. 2014, 45, 591-599. [CrossRef]

63. Griffin, D.R. The importance of atmospheric attenuation for the echolocation of bats (Chiroptera). Anim. Behav. 1971, 19, 55-61. [CrossRef]

64. Colbourne, R.; Baird, K.; Jolly, J. Relationship between invertebrates eaten by little spotted kiwi, Apteryx owenii, and their availability on Kapiti Island, New Zealand. N. Z. J. Zool. 1990, 17, 533-542. [CrossRef]

65. Brumm, H.; Slabbekoorn, H. Acoustic communication in noise. Adv. Study Behav. 2005, 35, 151-209. 
66. Mennill, D.J. Variation in the vocal behavior of Common Loons (Gavia immer): Insights from landscape-level recordings. Waterbirds 2014, 37, 26-36. [CrossRef]

67. Robbins, C.S. Effect of time and day on bird activity. Stud. Avian Biol. 1981, 6, 275-282.

68. Lengagne, T.; Slater, P.J. The effects of rain on acoustic communication: Tawny Owls have good reason for calling less in wet weather. Proc. Soc. B Biol. Sci. 2002, 269, 2121-2125. [CrossRef]

69. Zuberogoitia, I.; Burgos, G.; González-Oreja, J.A.; Morant, J.; Martínez, J.E.; Zabala Albizua, J. Factors affecting spontaneous vocal activity of Tawny Owls Strix aluco and implications for surveying large areas. Ibis 2019, 161, 495-503. [CrossRef]

70. Larom, D.; Garstang, M.; Payne, K.; Raspet, R.; Lindeque, M. The influence of surface atmospheric conditions on the range and area reached by animal vocalizations. J. Exp. Biol. 1997, 200, 421-431. [PubMed]

71. Clark, K.A.; Anderson, S.H. Temporal, climatic and lunar factors affecting owl vocalizations of western Wyoming. J. Raptor Res. 1997, 31, 358-363.

72. Swiston, K.A.; Mennill, D.J. Comparison of manual and automated methods for identifying target sounds in audio recordings of Pileated, Palebilled, and putative Ivory-billed Woodpeckers. J. Field Ornithol. 2009, 80, 42-50. [CrossRef]

73. Bobay, L.R.; Taillie, P.J.; Moorman, C.E. Use of autonomous recording units increased detection of a secretive marsh bird. J. Field Ornithol. 2018, 89, 384-392. [CrossRef]

74. Shonfield, J.; Heemskerk, S.; Bayne, E.M. Utility of automated species recognition for acoustic monitoring of owls. J. Raptor Res. 2018, 52, 42-55. [CrossRef]

75. Tomas, W.M.; de Oliveira Roque, F.; Morato, R.G.; Medici, P.E.; Chiaravalloti, R.M.; Tortato, F.R.; Penha, J.M.F.; Izzo, T.J.; Garcia, L.C.; Lourival, R.F.F.; et al. Sustainability agenda for the Pantanal wetland: Perspectives on a collaborative interface for science, policy, and decision-making. Trop. Conserv. Sci. 2019, 12. [CrossRef]

76. Por, F.D. The Pantanal of Mato Grosso (Brazil). In The World's Largest Wetlands; Kluwer Academic: London, UK, 1992.

77. Bird Life International. Claravis geoffroyi. (amended version of 2016 assessment). In The IUCN Red List of Threatened Species 2018; Bird Life International: Cambridge, UK, 2018.

Publisher's Note: MDPI stays neutral with regard to jurisdictional claims in published maps and institutional affiliations.

(C) 2020 by the authors. Licensee MDPI, Basel, Switzerland. This article is an open access article distributed under the terms and conditions of the Creative Commons Attribution (CC BY) license (http://creativecommons.org/licenses/by/4.0/). 